\title{
Thermal, Rheological and Mechanical Properties of PETG/rPETG Blends
}

\author{
Paulina Latko-Durałek ${ }^{1}$ (I) $\cdot$ Kamil Dydek $^{1} \cdot$ Anna Boczkowska $^{1}$
}

Published online: 28 August 2019

(c) The Author(s) 2019

\begin{abstract}
This paper presents the reuse process of post-consumer printed foils made of glycol-modified poly(ethylene terephthalate) (PETG). Fourier-transform infrared spectroscopy and a scanning electron microscope confirmed that these foils consist of PETG and PS layers. Firstly, foil pieces were immersed in the organic solution to remove all prints and after washing and drying they were extruded into regranulate rPETG pellets. Three types of PETG/rPETG blends were fabricated with the addition of 10, 20 and $30 \mathrm{wt} \%$ of virgin PETG. Microscopic analysis of the blends confirmed their homogeneity, as was also shown by the fact that there was only one glass transition peak in the heating curve given by differential scanning calorimetry. Moreover, in the presence of fresh PETG the degradation temperatures of PPETG improved significantly, and the viscosity of all blends was reduced as a result of shortened macromolecule chains in rPETG. Mechanical analysis of the materials showed that all blends have comparable tensile strength and a Young's modulus that is higher than rPETG but lower than virgin PETG. Elongation at break decreases together with the content of rPETG.
\end{abstract}

Keywords PETG $\cdot$ Mechanical recycling $\cdot$ Post-consumer foils $\cdot$ Polymer blends

\section{Introduction}

The problem of large amounts of waste is the result of everincreasing demand for plastic products, especially from the packaging industry. One example of common rubbish is polymeric foil with various types of colorful prints, which are used as labels on food and chemical packaging [1]. These foils are very often produced from PETG due to its high transparency resulting from its low content of crystalline phase, good mechanical properties and good chemical resistance [2,3]. Moreover, because PETG is an amorphous and linear polymer, it is an excellent material for extrusion, injection molding, blow molding and thermoforming. In recent years, PETG has also become popular in 3D printing [4].

Printing on polymeric films is mainly done using conventional inks, which are cheaper than ultraviolet curing inks. Organic, inorganic, natural and synthetic pigments give a specific color and opacity to the ink. Low molecular weight

Paulina Latko-Durałek

paulina.latko@pw.edu.pl

1 Department of Materials Science and Engineering, Warsaw University of Technology, ul. Wołoska 141, 02-507 Warsaw, Poland resins (binders) are used to disperse pigments, while a liquid carrier that evaporates after application on the foil is responsible for the inks' fluidity. There are also additives in the inks such as waxes, drying agents and surfactants [5]. The presence of so many different components in the inks hampers the recycling process of the films because they can decompose during processing into regranulate. Therefore, it is necessary to remove all prints and colors from waste foils using organic solvent or surfactant solutions to make them clear and easily processable $[1,6]$.

There are two ways of reprocessing thermoplastic foils: mechanical and chemical recycling. For mechanical recycling, collected plastic wastes are sorted, washed, ground, melted and compounded into regranulate pellets. For chemical recycling, the plastic wastes are converted into raw materials such as hydrocarbons, oils or monomers [7]. Most packaging films are multilayer foils consisting of 50\% polymer with other organic or metallic $\left(\mathrm{AlO}_{\mathrm{x}}, \mathrm{SiO}_{\mathrm{x}}\right)$ layers. Therefore, they should be firstly delaminated into basic components, which are then recycled in separate streams or processed directly using compatibilizers $[8,9]$.

Since the mechanical recycling process shortens the molecular chains, the recycled polymeric materials suffer from weaker mechanical properties [10]. Therefore, it is necessary to increase their mechanical strength by mixing 
with other (often fresh) polymers to create blends. Li et al. recycled PETG by breaking up, washing and heating pellets to $80{ }^{\circ} \mathrm{C}\left(\mathrm{T}_{\mathrm{g}}\right.$ of PETG) [11]. This PETG regranulate was then mixed with acrylonitrile-butadiene-styrene copolymer (ABS) by the extrusion method, thus resulting in enhanced tensile strength and ductility. Franciszczak et al. proposed a method of using recycled PETG with short PET fibers to obtain composites with improved mechanical properties [12]. In another work, PETG regranulate was mixed with polypropylene (PP) in the presence of three triblock copolymers (SEBS, SBS, SIS) to improve the interfacial adhesion between polymers [13].

The scope of this paper was to (i) identify the components of post-consumer PETG from various products' labels, (ii) recycle the foils into regranulate pellets and use them in blends with virgin PETG, and (iii) characterize the properties of these PETG/rPETG blends.

\section{Materials and Methods}

As a starting material, post-consumer color-printed PETG foil from various waste labels of bottles, boxes, cans, etc. was used. The mechanical recycling of the PETG foils is presented schematically in Fig. 1 and it was described in detail in our patent [14]. In the first step the foil was cut into small pieces and immersed in different organic solvents (heptane, toluene, propan-2-ol, cetyltrimethylammonium bromide, diacetone alcohol, acetone) to remove all prints from the surface. The selection of the appropriate diluent was achieved on a trial-and-error basis by keeping the foil in the solvent for $5 \mathrm{~min}$. The effectiveness of the solvent was measured by removing of all of the inks without destroying the foil; in turn, the most optimal shape of the squares was analyzed by cutting the foil into different dimensions, and it was found that $80 \mathrm{~mm}$ by $10 \mathrm{~mm}$ rectangular pieces resulted in the most effective removal of prints. Finally, an aqueous solution based on low-weight organic compounds and esters was selected. In the first step, the foil pieces were mixed for $3 \mathrm{~min}$ in the solution with a high-speed rotor stirrer, after which the solvent was refreshed, and the squares were mixed again for $3 \mathrm{~min}$. After washing in water, to remove the solvent the foil pieces were dried at $60{ }^{\circ} \mathrm{C}$ for $24 \mathrm{~h}$ in a vacuum oven. In the next step, the cleaned and dried pieces of foil were extruded using a laboratory twin-screw extruder (HAAKE MiniLab II ThermoScientific, Germany) equipped with conical screws working in co-rotating mode. The extrusion temperature was $190{ }^{\circ} \mathrm{C}$, screw velocity $80 \mathrm{rpm}$ and mixing time $3 \mathrm{~min}$; this resulted in good quality regranulate pellets (rPETG). Blends of rPETG were fabricated by mixing the regranulate with fresh, neat PETG pellets (Eastar ${ }^{\mathrm{TM}}$ copolyester 6763, Eastman Chemical, USA) using the same laboratory twin-screw extruder under the same processing

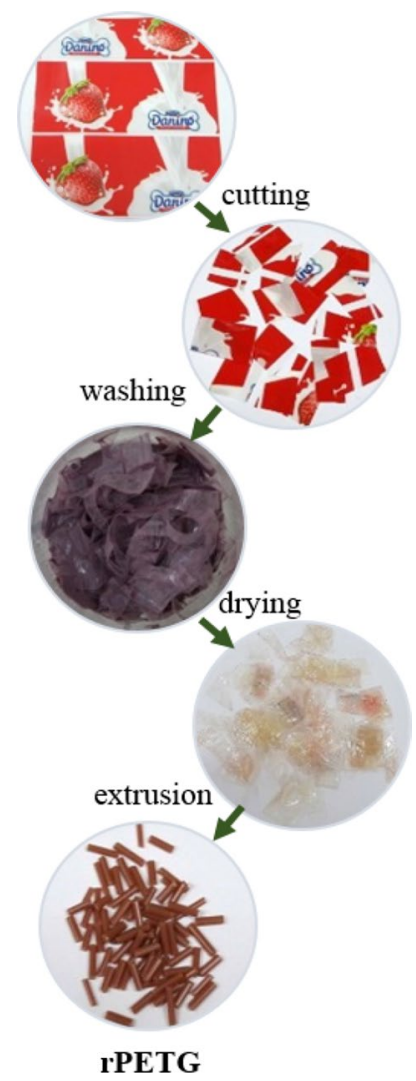

Fig. 1 Mechanical recycling process of PETG, starting from printed waste foils and ending with regranulate pellets

conditions. Three types of blends (PETG/rPETG) were prepared containing 10\%, 20\% and $30 \mathrm{wt} \%$ of rPETG. $100 \%$ rPETG and $100 \%$ of fresh PETG were used as reference materials.

In order to identify the number and character of the layers in the foil, the analysis was performed across the foil thickness using a Scanning Electron Microscope (SEM 3000 Hitachi, Japan). For the tests, samples were cut directly from the foil or fractured by immersion in liquid nitrogen. Both types of samples were then coated with a thin layer of gold to make them electrically conductive. The applied voltage was $5 \mathrm{kV}$ for all materials. The SEM method was also utilized to examine the microstructure of the cryo-fractured blends of rPETG/PETG.

In order to identify the components of the foils, Fourier Transform Infrared Spectroscopy (FTIR) was applied. Samples for the analysis were cut from different types of foil and FTIR spectra were collected using a Thermo Scientific Nicolet 6700 spectrometer with the attenuated total reflectance (ATR) technique. Each sample was scanned 64 times with a resolution of $4 \mathrm{~cm}^{-1}$ in the frequency range $4000-400 \mathrm{~cm}^{-1}$.

The thermal properties of all materials were tested. Thermogravimetric analysis was performed using a TGA Q500 thermogravimeter (TA Instruments, USA). Samples 
were tested at $800{ }^{\circ} \mathrm{C}$ under nitrogen at a combustion rate of $10^{\circ} \mathrm{C} / \mathrm{min}$. From the obtained thermogravimetric curves, a $2 \%$ weight loss temperature $\mathrm{T}_{2 \%}$, a $5 \%$ weight loss temperature $\mathrm{T}_{5 \%}$, and a maximum $\mathrm{T}_{\max }$ degradation temperature were determined. The glass transition temperature $\left(\mathrm{T}_{\mathrm{g}}\right)$ was determined by Differential Scanning Calorimetry (DSC) with a Q1000 calorimeter from TA Instruments (USA). Samples of approximately $9 \mathrm{mg}$ were placed in an aluminum pan. The following program was used: cooling to $-90{ }^{\circ} \mathrm{C}$, maintaining constant temperature for $5 \mathrm{~min}$ and then heating to $\left(\mathrm{T}_{5 \%}\right.$ $\left.-10{ }^{\circ} \mathrm{C}\right)$, cooling to $-90{ }^{\circ} \mathrm{C}$ and heating to $\left(\mathrm{T}_{5 \%}-10^{\circ} \mathrm{C}\right)$. The heating process was carried out at $10^{\circ} \mathrm{C} / \mathrm{min}$, while cooling was conducted at $5{ }^{\circ} \mathrm{C} / \mathrm{min}$.

Samples for rheological analysis were prepared directly from the pellets by injection molding into rounds with a thickness of $2 \mathrm{~mm}$ and diameter of $1.5 \mathrm{~mm}$, with parameters listed in Table 1. A dynamic oscillatory stress-controlled rotational test was performed in parallel plate geometry mode using an ARES rheometer (Rheometric Scientific Inc., Piscataway, USA). The test was carried out at $190{ }^{\circ} \mathrm{C}$, from 0.1 to $100 \mathrm{~Hz}$ and with $1 \%$ of strain determined from the amplitude sweeps test.

Static stretching tests were carried out on a standard strength machine (EZ-SX, Shimadzu, Japan), in accordance with the PN-EN ISO 527 standard. The dogbone samples were also made by injection molding with the parameters listed in Table 1 . The stretching speed was $10 \mathrm{~mm} / \mathrm{min}$ and the test was conducted at room temperature.

\section{Results}

The cross-section of printed post-consumer foil was analyzed by SEM to determine the number of layers. As shown in Fig. 2a, the used foil consists of five layers with a total thickness of around $52 \mu \mathrm{m}$. This is a typical example of multilayer foil used in the packaging industry as outer labels on various types of packaging. In the middle, there is the thickest $23.6 \mu \mathrm{m}$ layer, which is surrounded on both sides by thinner layers around $7 \mu \mathrm{m}$ thick. On the surface of the foil there is a coating of inks with an inhomogeneous thickness of around $1.4 \mu \mathrm{m}$, as shown in Fig. $2 \mathrm{~b}$.

Each of the foil layers was separated by hand and its composition was analyzed by FTIR. The obtained FTIR spectra for the two inner layers ( $7 \mu \mathrm{m}$ thick) and for the main one ( $23.6 \mu \mathrm{m}$ thick) are presented in Fig. 3 and it can be seen that they differ in composition. The weak peaks at $2931 \mathrm{~cm}^{-1}, 2919 \mathrm{~cm}^{-1}$ and $2848 \mathrm{~cm}^{-1}$ occur for both
Table 1 Injection molding conditions

\begin{tabular}{llllll}
\hline Material & $\begin{array}{l}\text { Cylinder tem- } \\
\text { perature }\left({ }^{\circ} \mathrm{C}\right)\end{array}$ & $\begin{array}{l}\text { Mold tem- } \\
\text { perature }\left({ }^{\circ} \mathrm{C}\right)\end{array}$ & $\begin{array}{l}\text { Injection time } \\
(\mathrm{s})\end{array}$ & $\begin{array}{l}\text { Injection } \\
\text { pressure (bar) }\end{array}$ & $\begin{array}{l}\text { Post } \\
\text { pressure } \\
\text { (bar) }\end{array}$ \\
\hline $100 \%$ PETG & 245 & 40 & 10 & 500 & 400 \\
$90 \%$ PETG-10\% rPETG & 235 & 40 & 10 & 550 & 400 \\
80\% PETG-20\% rPETG & 225 & 40 & 10 & 450 & 300 \\
$70 \%$ PETG-30\% rPETG & 220 & 40 & 10 & 400 & 300 \\
$100 \%$ rPETG & 190 & 40 & 10 & 300 & 250 \\
\hline
\end{tabular}

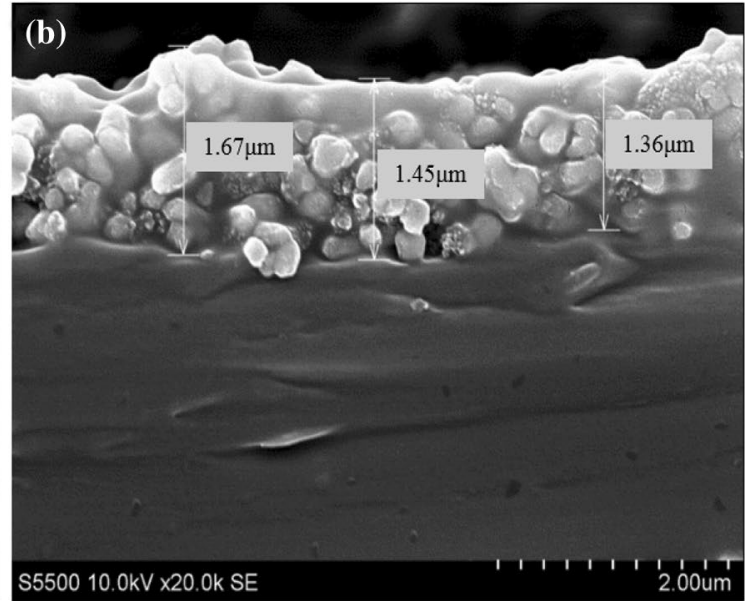

Fig. 2 Structure of post-consumer printed PETG foil: a Cross-section of the foil; $\mathbf{b}$ printed layer of the foil 

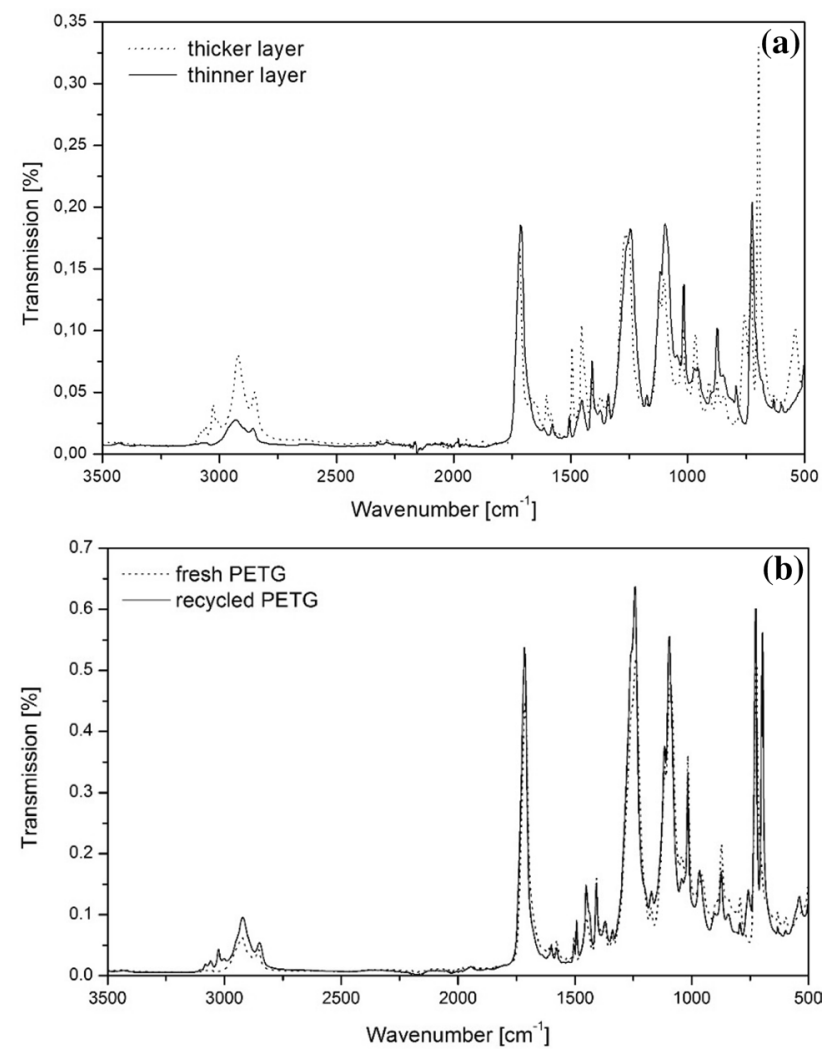

Fig. 3 FTIR spectra of a foil layers made of PETG and PS; $\mathbf{b}$ fresh and recycled PETG pellets

layers and indicate the asymmetric and symmetric $\mathrm{C}-\mathrm{H}$ stretching vibrations in the aliphatic polymeric chains. Additionally, for the thicker layer the peak at a higher wavelength $\left(3024 \mathrm{~cm}^{-1}\right)$ indicates the stretching vibrations of $\mathrm{C}-\mathrm{H}$ from the aromatic benzene rings $[15,16]$. In both spectra, strong peaks occur at $1717 \mathrm{~cm}^{-1}$ and $1712 \mathrm{~cm}^{-1}$, which is characteristic of the ester group $\mathrm{C}=\mathrm{O}$. Moreover, for the thinner layer the additional peak at $1243 \mathrm{~cm}^{-1}$ indicates the presence of ester groups; this was not found in the spectrum given for the thicker layer of the foil [17]. All weak peaks visible at $1600 \mathrm{~cm}^{-1}, 1577 \mathrm{~cm}^{-1}, 1504 \mathrm{~cm}^{-1}$, $1492 \mathrm{~cm}^{-1}$ and $1451 \mathrm{~cm}^{-1}$ are related to the stretching vibrations of the $\mathrm{C}-\mathrm{C}$ in the benzene rings; in turn, the peaks at $1100 \mathrm{~cm}^{-1}, 1095 \mathrm{~cm}^{-1}, 1018 \mathrm{~cm}^{-1}$ and $1017 \mathrm{~cm}^{-1}$ indicate the in-plane vibrations of $\mathrm{C}-\mathrm{H}$ bonds $[18,19]$. These peaks were found in the FTIR spectrum of both layers. The characteristic and strong peak visible at $723 \mathrm{~cm}^{-1}$ for the thinner layer shows that the benzene ring is disubstituted in the out-of-plane deformation of these carbonyl groups. The FTIR spectrum showed that the thicker layer possessed two characteristic peaks at $756 \mathrm{~cm}^{-1}$ and $696 \mathrm{~cm}^{-1}$ related to mono substitution of the aromatic ring [20]. Based on the FTIR analysis, it was found that the thinner layers of the foils consist of PETG, but the thicker layer is made of polystyrene (PS), which was probably used to increase the mechanical strength of the foil.

FTIR and SEM analyses were repeated for many types of post-consumer foil labels from various products (e.g. teas, yoghurts, detergents) to ensure that the starting material for the recycling process was homogenous in content. It was confirmed that these waste foils were composed mainly of PETG with some PS. In mechanical recycling using the extrusion method, the pieces of the foils were used without separation of their layers. There were no problems during extrusion of the foil into the regranulate or during mixing of rPETG with virgin PETG into blends. Comparison of the regranulate pellets with fresh PETG showed no chemical changes in the structure of the PETG after washing with organic solvent and after the extrusion process. This was confirmed by the FTIR spectra collected in Fig. 3b. Similar results have been described in the literature for PET recycled mechanically many times [21, 22]. Obviously the weakness of the peaks could be related to the shortening of the PETG chains and consequent decrease of the molecular weight of the polymers, as is characteristic of regranulates [23].

The fracture surface of the PETG/rPETG pellet blends obtained by SEM analysis is shown in Fig. 4 at $\times 3000$ magnification. Generally, the morphology of all blends looks similar, without any defects or discontinuity. There are only some tiny pores which probably appear as an effect of solvent evaporation during extrusion process. It should be mentioned that in each blend some amount of PS is introduced from the basic layer of the foil. It is known that PS and PETG are immiscible due to the poor interfacial adhesion between them, therefore chemical compatibilizers are used to form more homogenous interfaces [24]. However, based on SEM images it is seen that all components (rPETG, fresh PETG and PS) had been successfully mixed, thus resulting in homogenous structure. This means that the amount of PS is lower than the total content of PETG and therefore the prepared blends consist of a continuous PETG matrix with evenly dispersed PS domains.

The thermal properties of virgin PETG, rPETG and their blends were characterized by TGA and DSC. As shown by the results collected in Table 2, rPETG starts to degrade at a much lower temperature $\left(\mathrm{T}_{2 \%}=166^{\circ} \mathrm{C}\right)$ than fresh PETG $\left(\mathrm{T}_{2 \%}=366^{\circ} \mathrm{C}\right)$ due to shortening of the polymer chains after the recycling process. This obviously precludes the usage of $100 \%$ rPETG in practical applications, therefore it was mixed with virgin PETG, which resulted in an increase of the degradation temperature of about $133{ }^{\circ} \mathrm{C}$ to $299{ }^{\circ} \mathrm{C}$ for a blend containing $70 \mathrm{wt} \%$ PETG. For $80 \mathrm{wt} \%$ and $90 \mathrm{wt} \%$ PETG the degradation temperature at $2 \%$ loss of the material weight is $321{ }^{\circ} \mathrm{C}$ and $323{ }^{\circ} \mathrm{C}$, respectively. The differences in the temperature values of the fastest degradation between rPETG and PETG is $40{ }^{\circ} \mathrm{C}$. As is shown in Fig. 4, all blends have a homogenous morphology that indicates 

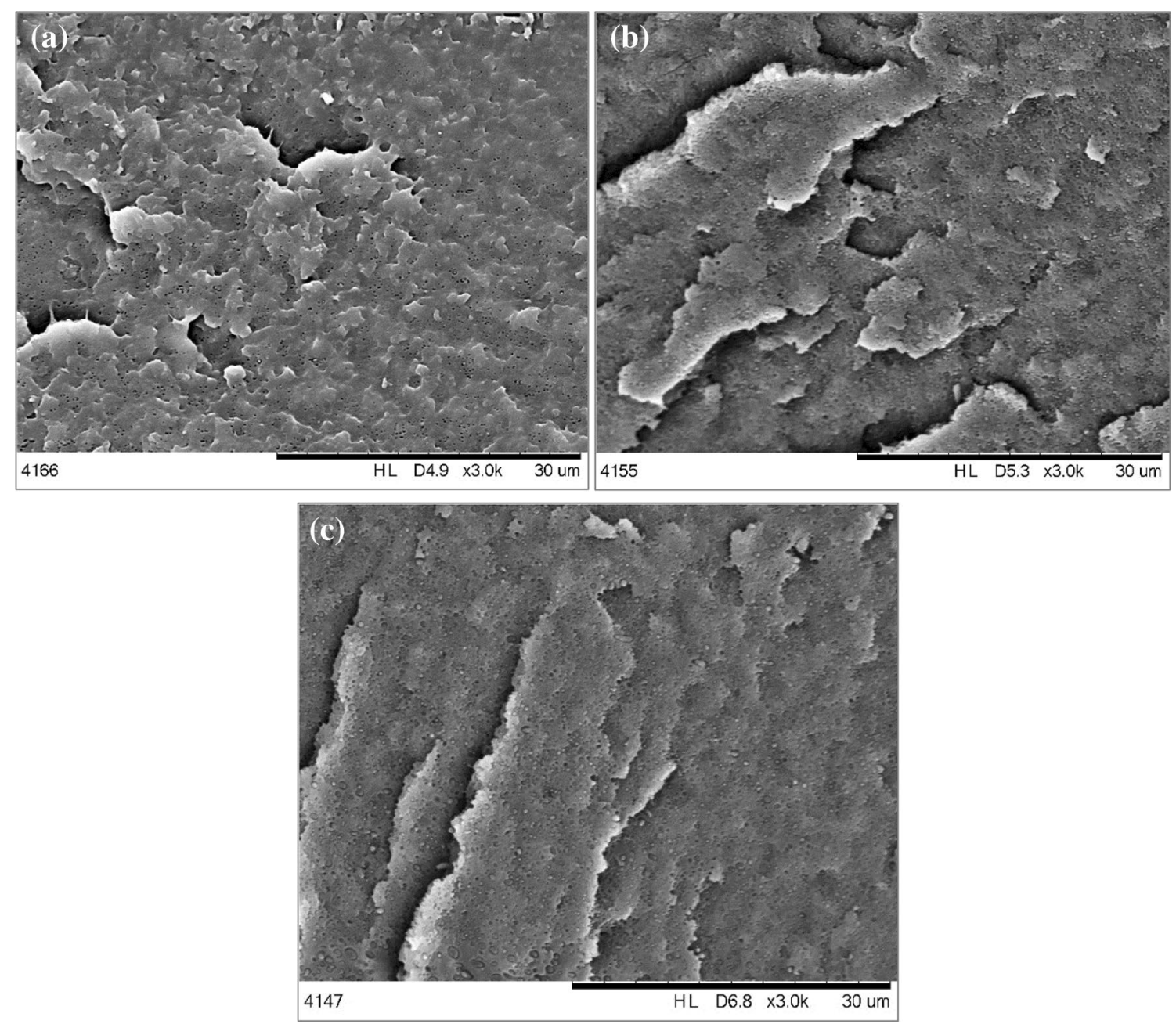

Fig. 4 SEM images of cryo-fractured pellets of: a 90\% PETG-10\% rPETG, b 80\% PETG-20\% rPETG, c 70\% PETG-30\% rPETG

Table 2 Thermal properties of tested materials determined from TGA and DSC analysis

\begin{tabular}{lllll}
\hline Material & $\mathrm{T}_{2 \%}\left({ }^{\circ} \mathrm{C}\right)$ & $\mathrm{T}_{5 \%}\left({ }^{\circ} \mathrm{C}\right)$ & $\mathrm{T}_{\max }\left({ }^{\circ} \mathrm{C}\right)$ & $\mathrm{T}_{\mathrm{g}}\left({ }^{\circ} \mathrm{C}\right)$ \\
\hline 100\% PETG & 366 & 378 & 420 & 75 \\
90\% PETG-10\% rPETG & 323 & 344 & 393 & 73 \\
80\% PETG-20\% rPETG & 321 & 343 & 390 & 73 \\
70\% PETG-30\% rPETG & 299 & 340 & 381 & 72 \\
$100 \%$ rPETG & 166 & 275 & 380 & 49 \\
\hline
\end{tabular}

good mixing of the components (PETG and PS). The heating curves presented in Fig. 5 shows that there is only one glass transition peak, which thus verifies the homogeneity of the blends. The highest $\mathrm{T}_{\mathrm{g}}$ is observed for fresh PETG $\left(75^{\circ} \mathrm{C}\right)$, while the lowest is for $\operatorname{rPETG}\left(49^{\circ} \mathrm{C}\right)$ what is typical for the polymers after recycling process [25]. A small addition of $\mathrm{rPETG}$ slightly reduces the value of $\mathrm{T}_{\mathrm{g}}$ in comparison to fresh PETG. For all blends, glass transition temperatures are

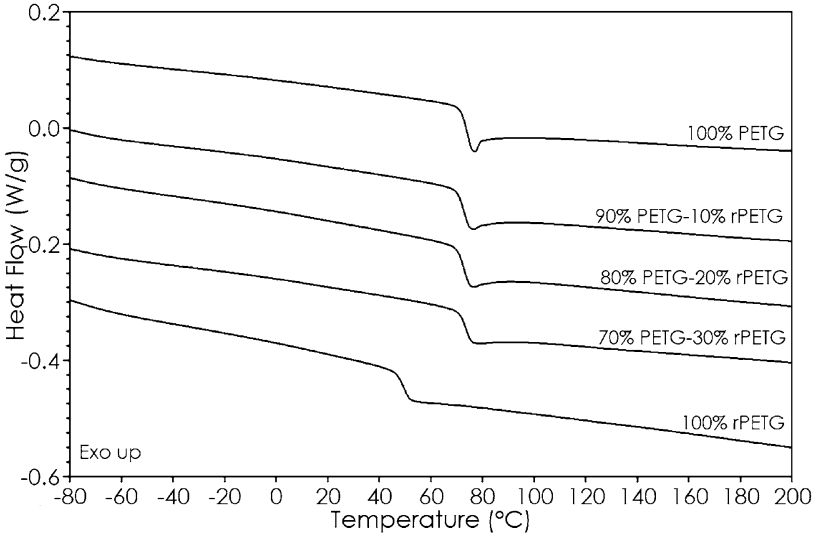

Fig. 5 DSC curves from the second heating

negligibly lower in comparison to virgin PETG. In case of $100 \%$ rPETG, such low $\mathrm{T}_{\mathrm{g}}$ is caused by the presence of residue of solvent which also has an effect on the pores visible in 


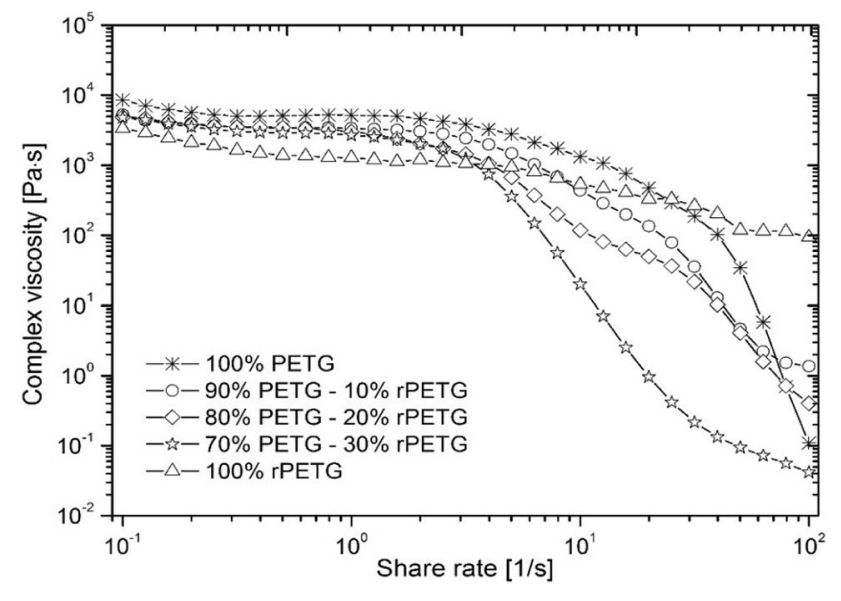

Fig. 6 Complex viscosity as a function of share rate

the SEM images in the blends (Fig. 4). In addition, multiple processing steps reduce the lengths of the macromolecule chains and therefore rPETG is more elastic than 100\% PETG and the blends.

The main processing parameter is the viscosity of the polymer at the extrusion temperature. Therefore, the effect of the addition of rPETG on the rheological properties of fresh PETG was analyzed at $190{ }^{\circ} \mathrm{C}$. Figure 6 presents the variation of the complex viscosity for PETG, rPETG and their blends in dependence on a shear rate. For all tested materials, as is characteristic of Newtonian fluids, the viscosity is linear at a low shear rate, but at higher frequencies it decreases typically as for non-Newtonian liquids [26]. rPETG is less viscous than fresh PETG at lower frequencies due to the shorter macromolecular chains. Therefore, the viscosity of blends increased along with the presence of rPETG and was lowest for the blend that contained $30 \mathrm{wt} \%$ of rPETG. Such a linear dependence between the viscosity of the blends and the content of used components was also found for recycled HDPE/virgin polyolefin blends [27]. From a practical point of view, PETG/rPETG blends with reduced viscosity can be easily processable by extrusion, thermoforming, injection molding or blow molding into sheets, films, covers, 3D filaments, packaging, containers, etc.

The mechanical properties of the blends were analyzed and compared against virgin PETG and 100\% rPETG using samples after injection molding. According to Fig. 7, the tensile strength slightly decreases as the amount of rPETG content in the blend increases. The amount falls by $2-3 \mathrm{MPa}$ even with the addition of $30 \%$ rPETG, but when compared to $100 \%$ rPETG there is an increase of about $22 \mathrm{MPa}$ for the same blend. In the case of Young's Modulus, the situation is similar to the tensile strength because all blends are only slightly less stiff than fresh PETG, but stiffer than rPETG. The reduction of the blends' tensile strength and their
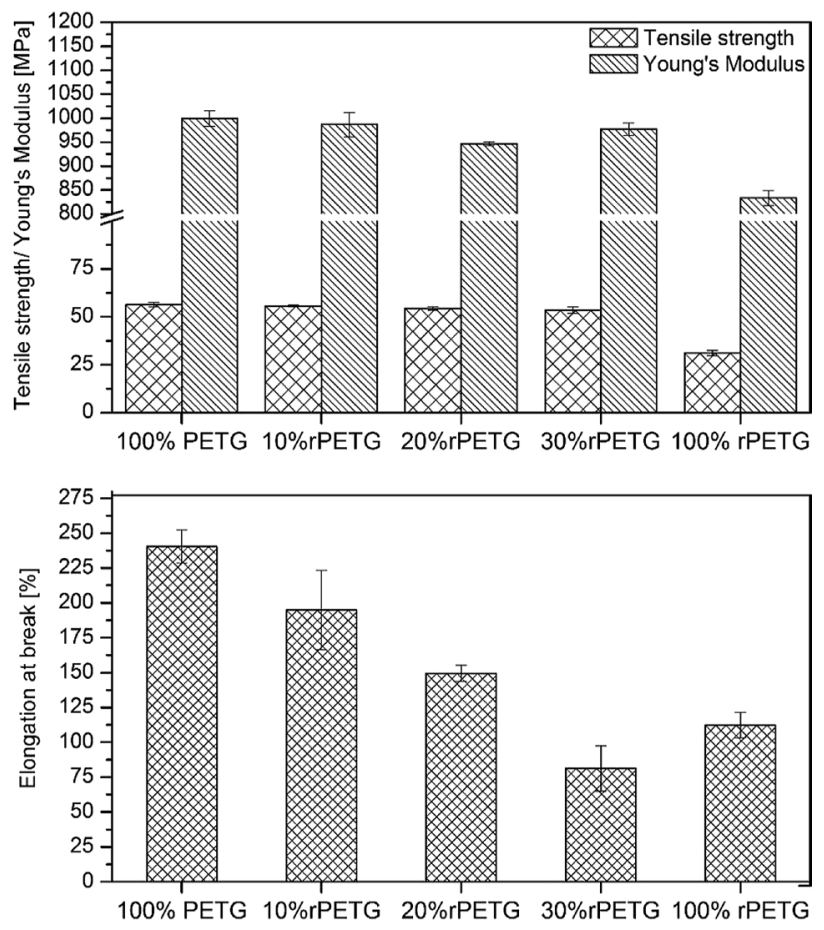

Fig. 7 Mechanical properties of rPETG/PETG blends and their comparison to $100 \%$ of fresh and recycled PETG

Young's Modulus is due to the addition of rPETG, which has low mechanical strength and stiffness. Figure 7 shows a much stronger decline in elongation at break for PETG/ rPETG blends that is associated with the shorter chains in rPETG. For 30wt \% rPETG the decrease is from $240 \%$ (for fresh PETG) to $81 \%$; even though this blend contains virgin PETG, its elongation at break is lower than for $100 \%$ rPET, which theoretically should have the lowest elongation. Similarly, a significant decrease in the elongation of recycled PC/ ABS blends has been reported by Liang and Gupta [28], who also observed a negligible loss of tensile strength.

\section{Conclusions}

In the presented paper the mechanical recycling process of post-consumer PETG foils involves the removal of colored prints using an organic solution and then extrusion the clear foil pieces to form regranulate pellets. Using FTIR and SEM analysis it was found that the waste foils coming from various product labels consist of a thin layer of PETG and a thick layer which was found to be PS. Formulation by extrusion of the blends containing 10, 20 and $30 \mathrm{wt} \%$ of rPETG resulted in homogenous morphology, which indicates that all components (rPETG, PETG, PS) are fully miscible. Thermal analysis of the blends showed a lower glass transition peak for rPETG $\left(\mathrm{T}_{\mathrm{g}}=49^{\circ} \mathrm{C}\right)$ than for PETG/rPETG blends 
$\left(\mathrm{T}_{\mathrm{g}}=73{ }^{\circ} \mathrm{C}\right)$ and virgin PETG $\left(\mathrm{T}_{\mathrm{g}}=75^{\circ} \mathrm{C}\right)$ that is related to some trace amount of solvent or prints in rPETG. The addition of $70 \mathrm{wt} \%$ PETG increased the decomposition temperature of rPETG by about $133^{\circ} \mathrm{C}$, which was in turn $67^{\circ} \mathrm{C}$ lower than for virgin PETG. Since rPETG has shortened macromolecule chains, the viscosity of the blend decreases as the amount of rPETG increases. The poor mechanical strength of rPETG was improved by the addition of fresh PETG. The tensile strength for blend containing $30 \mathrm{wt} \%$ rPETG increased by about $42 \%$, Young's Modulus increased by about $15 \%$ and elongation at break increased by about $27 \%$ in comparison to $100 \%$ rPETG.

Acknowledgements The work was carried out under Grant No. GEKON2/05/266860/24/2016, financed by The National Centre for Research and Development as well as The National Fund for Environmental Protection and Water Management.

Open Access This article is distributed under the terms of the Creative Commons Attribution 4.0 International License (http://creativeco mmons.org/licenses/by/4.0/), which permits unrestricted use, distribution, and reproduction in any medium, provided you give appropriate credit to the original author(s) and the source, provide a link to the Creative Commons license, and indicate if changes were made.

\section{References}

1. Ashutosh Mukhopadhyay (2015) Process for delamination of laminated packaging. US 8, 945, $396 \mathrm{~B} 2$

2. Li B, Zhang X, Zhang Q, Chen F (2009) Synergistic enhancement in tensile strength and ductility of ABS by using recycled PETG plastic. J Appl Polym Sci 113:1208-1215

3. Badia JD et al (2012) The role of crystalline, mobile amorphous and rigid amorphous fractions in the performance of recycled poly (ethylene terephthalate) (PET). Polym Degrad Stab 97(1):98-107. https://doi.org/10.1016/j.polymdegradstab.2011.10.008

4. Chen T, You H (2016) RSC Advances photodegradation behavior and mechanism random copolymers: correlation with copolymer composition. RSC Adv R Soc Chem 6:102778-102790. https:// doi.org/10.1039/C6RA21985C

5. Czarnecka-Komorowska D, Ciesielska D (2005) Wpływ liczby obiegów na właściwości recyklatów polimerowych. Inżynieria i Aparatura Chemiczna 44(3s):16-17

6. Franciszczak P, Piesowicz E, Kalni K (2018) 'Manufacturing and properties of r-PETG/PET fi bre composite-novel approach for recycling of PETG plastic scrap into engineering compound for injection moulding. Compos B 154:430-438. https://doi. org/10.1016/j.compositesb.2018.09.023

7. Gecol H et al (2003) Use of surfactants to remove solvent-based inks from plastic films. Colloid Polym Sci 281(12):1172-1177. https://doi.org/10.1007/s00396-003-0891-4

8. Ignatyev IA, Thielemans W, Vanderbeke B (2014) Recycling of polymers : a review. ChemSusChem 7(6):1579-1593. https://doi. org/10.1002/cssc. 201300898

9. Jang J, Lee K (2002) (2002) 'Facile fabrication of hollow polystyrene nanocapsules by microemulsion polymerization. Chem Commun 10:1098-1099
10. Kadac K, Jacek J, Nowaczyk, N (2015) Wpływ procesu recyklingu na właściwości poli(tereftalanu etylenu) Przetwórstwo Tworzyw 4:329-332

11. Kaiser K, Schmid M, Schlummer M (2018) Recycling of polymerbased multilayer packaging: a review. Recycling 3(1):1-26. https ://doi.org/10.3390/recycling3010001

12. Liang RF, Gupta RK (2002) Processing and characterization of recycled PC/ABS blends with high recycle content. SPE ANTEC, pp 2948-2952

13. Liangt CY, Krimm S, Randall HM (2000) Infrared spectra of high polymers. VI. Polystyrene J Polym Sci 27(1958):241-254

14. Miller $P$ et al (2001) Rheological properties of blends of recycled HDPE and virgin polyolefins. Polym Recycl 6(4):181-186

15. Paszkiewicz $\mathrm{S}$ et al (2017) Synthesis and characterization of poly (ethylene terephthalate-co-1, 4-cyclohexanedimethylene terephtlatate)-block-poly (tetramethylene oxide) copolymers. RSC Adv R Soc Chem 7(66):41745-41754. https://doi.org/10.1039/ c7ra07172h

16. Piecyk L (2006) PETG—modyfikowany PET w produkcji opakowań. Opakowanie 9(51):54-57

17. Piesowicz, E. et al. (2014) A method of recovering polymer from printed PETG substrates.

18. Ragaert K, Delva L, Geem K Van (2017) Mechanical and chemical recycling of solid plastic waste. Waste Manag 69:24-58. https ://doi.org/10.1016/j.wasman.2017.07.044

19. Ronkay F (2013) Effect of recycling on the optical, mechanical and structural properties of polypropylene fibers. Acta Polytech Hung 10(1):209-220. https://doi.org/10.1016/j.optla seng.2013.02.018

20. Satas D, Tracton AA (2001) Coatings technology handbook, 2nd edn. Marcel Dekker Inc., New York

21. Schramm, G. (1994) A practical approach to rheology and rheometry, Rheology, p. 291. https://www.polymer.cn/bbs/File/UserF iles/UpLoad/200904010309415s.pdf.

22. Szykiedans K, Credo W, Osi D (2017) Selected mechanical properties of PETG 3-D prints. Proc Eng 177:455-461. https://doi. org/10.1016/j.proeng.2017.02.245

23. Tartakowski Z (2017) Właściwości wielokrotnie przetwarzanych kompozytów recyklatowych PVB/PP. Przetwórstwo Tworzyw 4:324-331

24. Vijayakumar S, Rajakumar PR (2012) Infrared spectral analysis of waste pet samples. Int Lett Chem Phys Astronomy 4:58-65

25. Wang W et al (2017) RSC Advances poly (ethylene terephthalate glycol) blending generation for controlled foaming behavior. RSC Adv R Soc Chem 7:39138-39146. https://doi.org/10.1039/C7RA0 7297J

26. Wiacek M, Wesolek D, Rojewski S (2015) Boronated (co) polystyrene: monomer reactivity ratios, thermal behavior and flammability. Polym Adv Technol. https://doi.org/10.1002/pat.3418

27. Zhang $X$ et al (2009) The effect of interfacial adhesion on the impact strength of immiscible PP/PETG blends compatibilized with triblock copolymers. Polymer 50(19):4737-4744. https://doi. org/10.1016/j.polymer.2009.08.004

28. Zimniak J (2011) Recykling materiałowy folii termoplastycznych stosowanych w przemyśle opakowaniowym i rolno-spożywczym. Inżynieria i Aparatura Chemiczna 50(3):95-96

Publisher's Note Springer Nature remains neutral with regard to jurisdictional claims in published maps and institutional affiliations. 